\title{
Beyond 'Earlygold': Juice Color and Quality of Additional Early-Maturing Sweet Orange Selections ${ }^{1}$
}

\author{
William S. Castle²
}

\section{Introduction}

This publication summarizes 5 years of juice quality information about 15 early-maturing sweet orange selections introduced to Florida and evaluated after 'Earlygold' became available. The trees were grown at a central Florida and Indian River location for about 10 years. Also presented are observations on tree development summarized across both locations and two rootstocks. Among the selections there were at least two, 'Rosa' and 'Seleta Branca', whose combined attributes favor further commercial evaluation. Commercial citrus producers and processors might find this publication useful because of the cultivars' earliness in maturity, excellent juice color, and good flavor, while homeowners might enjoy a more flavorful and attractive fruit than 'Hamlin' for the dooryard.

Sweet oranges grown in Florida are primarily used for juice products. There are two dominant cultivars-'Hamlin', which matures in the early part of the season, and 'Valencia', which is generally harvested between March and June. Of these two cultivars, 'Hamlin' is the most problematic or in need of improvement because, while trees are productive, the juice is of relatively low quality. The soluble solids content is low and juice color is poor, resulting in a juice with a flavor normally ranked well below that of 'Valencia'.
In fact, 'Hamlin' juice often fails to meet legal standards for quality and color, so it is often blended with higher-quality juice with better color, like 'Valencia', to make a Grade A product of commerce (see "Juice Color" below).

A long-standing desire of Florida citrus growers has been to have a productive early-season cultivar that has excellent juice quality and flavor. Such a cultivar would represent a combination of the best attributes of both 'Hamlin' and 'Valencia'. A search to achieve that objective has been under way for many years via various plant improvement techniques. In recent years, the University of Florida's citrus plant improvement team, which is comprised of Drs. F. Gmitter, J. Grosser, and W. Castle at the Citrus Research and Education Center (CREC) in Lake Alfred, has made two sweet orange cultivars available to the industry: 'Valquarius', a midseason 'Valencia'-type that originated from a collection of somaclones (Grosser 2010), and 'Earlygold', an early-maturing cultivar that emerged from a field trial comprising selections introduced from various places by seed (Castle and Baldwin 2011). In a follow-up study, another set of selections, also derived from introduced seed, was evaluated. Juice quality results from that study are also reported in this publication.

1. This document is HS1209, one of a series of the Horticultural Sciences Department, Florida Cooperative Extension Service, Institute of Food and Agricultural Sciences, University of Florida. Original publication date January 2013. Visit the EDIS website at http://edis.ifas.ufl.edu.

2. William S. Castle, professor emeritus, Horticultural Sciences Department, Citrus Research and Education Center, Florida Cooperative Extension Service, Institute of Food and Agricultural Sciences, University of Florida, Lake Alfred, FL, 33850.

The author wishes to acknowledge the contribution of Tom Hammond, Vero Beach citrus grower, who provided one of the sites and tree care in the evaluation study. Appreciation is also extended to Dr. Dan King, FL Dept. of Citrus, who reviewed the manuscript and provided assistance with regulatory aspects; and Cheryl Nagle, Tropicana, and Dave Crumbly, Florida's Natural, who both reviewed the manuscript and added a very helpful commercial perspective and accuracy. 


\section{Description of Field Study}

The original field trial that included 'Earlygold' was followed by two additional demonstration-type plantings of selections introduced from Brazil as seed. Fifteen selections were chosen from a book describing their traits (Donadio, de Figueiredo, and Pio 1995), as well as from recommendations of colleagues and grower-cooperators in Brazil. About 50-100 12-month-old seedlings (first generation) of each selection were the source of buds to propagate trees (second generation) on Carrizo citrange (a sweet orange-trifoliate orange hybrid) or US 809, a Changsha mandarin (Citrus reticulata Blanco) x Poncirus trifoliata (L.) Raf. 'English Large' hybrid. One set of trees, predominantly on US 809, was planted in May 1999 at the CREC, Lake Alfred, a central Florida location. The second set, primarily on Carrizo citrange, was established in September 1999 with a commercial grower in Vero Beach, an Indian River location. Neither set of plants was established in a formal replicated trial, but the trees of each selection were planted in at least two groups of about three to five trees each.

\section{Data}

Tree growth and development were observed, not measured. Because the trees were propagated using buds from young seedlings, they were more juvenile than standard nursery trees. Although juvenility was not a major factor in the previous field trial (Castle and Baldwin 2011), fruit sampling was not initiated until the 2004-05 season when the trees were about 5 years old. Sampling of about 50 fruit per "replication" of each selection in each season usually began in late October, followed by additional monthly samples in November, December, and sometimes January. Fruit sampling was not consistent from year to year across all selections because of differences in cropping; also, as tree size increased, collecting fruit became more difficult in some instances. These relatively juvenile trees typically tended to produce their crop at the edges of their canopy. Fruit, especially when there was a light crop, were often in the top of the tree, making it unwieldy to harvest. Juice was extracted from all samples and analyzed at the CREC with standard commercial equipment.

Examining and interpreting the figures. Note that in Figures 1, 3, 4, and 5, the data are sorted according to the November sampling date (black bars). Missing bars for a given selection mean that multiple sampling was limited by a small crop. As a result, sampling in November and later dates was emphasized. Also, the selection for comparison is 'Seleta Vermelha', which is virtually the same as 'Earlygold'.

\section{Results}

\section{Tree Development}

When fruit sampling was discontinued, the trees were 10 years old and most were about 20 feet tall. Their juvenile nature was well expressed in all selections, in that shoot flushes were vigorous and very thorny and the trees were somewhat upright in stature. Cropping began when the trees were about 3 years old, but not uniformly across all selections. By the time they were in their fifth season, all trees were producing enough fruit to begin sampling.

\section{Yield}

Tree productivity was not measured, but within 6 years after planting, many trees at both locations were producing an estimated two to three $90 \mathrm{lb}$. boxes of fruit per tree. Also, an indirect estimate of yield was related to sampling dates. Those selections with the most fruit were generally those that were sampled on three dates; selections with less fruit or fruit that was more difficult to harvest were sampled only on one or two dates.

\section{Juice Color}

Orange juice used in processed products must meet certain legal standards, including one for color as set forth in the U.S. Department of Agriculture Standards for Grades of Orange Juice (Fellers 1990). Juice is scored on a 100-point system with 40 points assigned to color, 40 points to flavor, and 20 points to "defects," referring to a measure of the absence of defects, such as pieces of peel in the juice. Juice color is measured on a colorimeter that produces a value known as the numeric color value or color number. Rounding off of the color number is allowed (e.g., an instrument reading [color number] of 35.6 can be rounded off to a USDA color score of 36) (State of Florida Department of Citrus 2010).

Understanding the terminology of the scoring system is important because both color number and color score are of practical significance in commerce. Typically, the color number (not color score) and other attributes are considered when batches of unblended juice are combined via proprietary algorithms to make the final product for packaging. However, for a juice product like pasteurized orange juice to be classified as Grade A, it must have a minimum score of 36 among the 40 points assigned to color. Therefore, one criterion for evaluating the selections reported herein is color numbers in the range of 35.0-36.4 that round off to a legal color score of 36 . However, note that while a high color number is desirable because it allows more flexibility in the juice blending business, or may even 
allow a juice to "stand alone," there may be other attributes like flavor that make the juice of a particular selection more useful than just its color.

In November of the 2007-08 season, many of the 15 selections at each location had color numbers equal to 35 or higher (Figs. 1 and 2). Those selections with the highest color numbers included 'Rosa', 'Seleta Branca', 'Seleta Vermelha' ('Earlygold'), and 'Seleta Agrocitros' at the Vero Beach site. In many cases, the color number appeared to be largely unaffected by location or rootstock for a given selection. Also, color numbers of some selections decreased between November and December, perhaps in conjunction with declining fruit maturity, suggesting that those selections peaked before late December/early January. As they began to decline, juice color apparently began to fade as well.

During the 2008-09 season, many selections achieved a color number $\geq 35$ by mid-November as in the previous season, and the numbers of some selections increased in December. Some of the same selections were among those with the highest color numbers, including the standard of comparison, 'Seleta Vermelha,' 'Seleta Branca', and 'Rosa'.

\section{Juice Soluble Solids}

As with juice color score, there is a "magic number" for soluble solids concentration for pasteurized orange juice or the popular product known as "Not from Concentrate." The standard of identity for orange juice is 11.0 , which is the minimum value required for Grade A juice.

Soluble solids concentrations ranged from 9.5 to 12.0 in November in the 2007-08 season and were generally higher at Lake Alfred than Vero Beach, where only three selections, one of them being 'Rosa', had values above 11.0 (Fig. 3). In the following season, soluble solids values were generally higher at Vero Beach, where nearly half of the selections had values above 11.0, but there were only four such selections among those at Lake Alfred. The values from 'Rosa' trees were among the highest, especially those on US 809 versus Carrizo citrange rootstock at Lake Alfred. Unlike juice color, soluble solids concentration increased between November and December by as much a one percentage point with many selections.

\section{Juice Pounds-Solids/Box}

In the Florida orange juice business, the currency of commerce is the quantity of soluble solids or pounds-solids (PS) in a box (90 lb.) of fruit. The processor pays the grower based on that measurement, which is calculated as: PS/box
$=$ no. boxes $\times$ lb. of juice $/$ box $\times$ soluble solids concentration of the juice. Early-season oranges ('Hamlin') typically have 5.0-5.5 PS per box in mid-November, which is usually before the processing season begins. Most selections at both locations and in both years had values above 5.0 in midNovember (Fig. 4). Fruit from the 'Rosa' and 'Earlygold' trees had some of the highest values, which were above 6.0 at Lake Alfred in both seasons.

PS/box values of some selections improved between November and December but declined for others. For those selections, the lower PS values in December were probably the result of a loss in juice content as observed from casual field tasting during sampling. A loss in juice content might also directly contribute to an increase in soluble solids concentration.

\section{Juice Ratio}

The ratio of soluble solids concentration to acid content is a key factor determining the flavor and palatability of a juice and, thus, fruit maturity. The Florida requirements for Grade A pasteurized orange juice are a minimum ratio of 12.5 and a maximum of 20.5. All the selections at both locations in each season met the minimum requirement in November, and a few selections exceeded the maximum (Fig. 5). The difference among selections can be expressed in terms of grower and processor experience with fruit maturity. Growers have observed that ratio advances about $1 / 2$ point per week, or 2 points per month. Thus, at Lake Alfred in 2008-09, the difference in ratio between 'Seleta Branca' and 'Seleta Vermelha' ('Earlygold') may represent about a month's difference in fruit maturity. Such a difference may not be useful in the juice business. The opening of processing facilities is currently linked to 'Hamlin' fruit maturity. However, a 30-day difference in fruit maturity among early-season cultivars might be important in the fresh fruit market.

\section{Promising Selections}

The selections deemed most promising were 'Rosa' and 'Seleta Branca', based on the best and most consistent combination of results for juice color, soluble solids concentration, and pounds-solids production. The promising selections did not necessarily exhibit the highest results for each variable evaluated, but their combined results compared favorably with 'Seleta Vermelha' and 'Hamlin' (Table 1). Furthermore, a major juice processing company has been assessing these promising selections along with 'Seleta Agrocitros'. Each selection has ranked well for flavor in comparison with 'Hamlin.' 


\section{Caveats}

Virtually all the selections evaluated should be considered truly early-maturing and different from 'Hamlin' in that regard. 'Hamlin' fruit can be stored on the tree from the time they reach the minimum juice standards required for harvest (November) until well into January, if not early February. The new cultivars described in this report appear to require harvest not later than the end of December before fruit quality declines. Loss of quality may be substantially due to their juvenile nature; thus, the trees and fruit in subsequent generations propagated from more mature budwood may more fully express their potential.

Canker. When 'Earlygold' became available to the industry in the mid-1990s, the most serious outbreak of canker disease was just beginning. As the new cultivar made its way into commerce, it was eventually proved to be at least as susceptible as 'Hamlin' (Graham 2001). The new selections described in this report have not been formally tested for their tolerance to canker; however, some evidence from other field trials suggests that they are performing as other early-season oranges.

Yield. Tree productivity was not measured, but yield is a critical component of the commercial potential of any new cultivar.

\section{Budwood Availability}

Limited quantities of all the selections are available from the CREC repository. No selections have been entered into the Citrus Budwood Registration Parent-Tree Program, but the repository trees are legal sources of buds to produce trees for field trials. 'Earlygold' is maintained in the Budwood Office Foundation Block, Chiefland.

\section{References}

Castle, W. S., and J. C. Baldwin. 2011. "Young-Tree

Performance of Juvenile Sweet Orange Scions on Swingle

Citrumelo Rootstock." HortScience 46 (4): 541-552.

Donadio, L. C., J. O. de Figueiredo, and R. M. Pio. 1995.

Variedaes Citricas Brasileiras. Jaboticabal, Brazil: Funep/ Unesp.

Fellers, P. F. 1990. “Florida’s Juice Standards for Grades and Their Differences from United States Standards for Grades and United States Food and Drug Administration Standards of Identity." Proc. Fla. State Hort. Soc. 103: 260-265.

State of Florida Department of Citrus. 2010. "Official Rules Affecting the Florida Citrus Industry.” 2010. https:// fdocgrower.box.com/shared/ajohqqo8z25neephpgpy.

Graham, J. H. 2001. "Varietal Susceptibility to Citrus Canker: Observations from Southern Brazil." Citrus Ind. 82 (6): 15-17.

Grosser, J. W. 2010. "'Valquarius." New Varieties Development and Management Corporation. http://nvdmc.org/ nvdmcmanaged.html. 

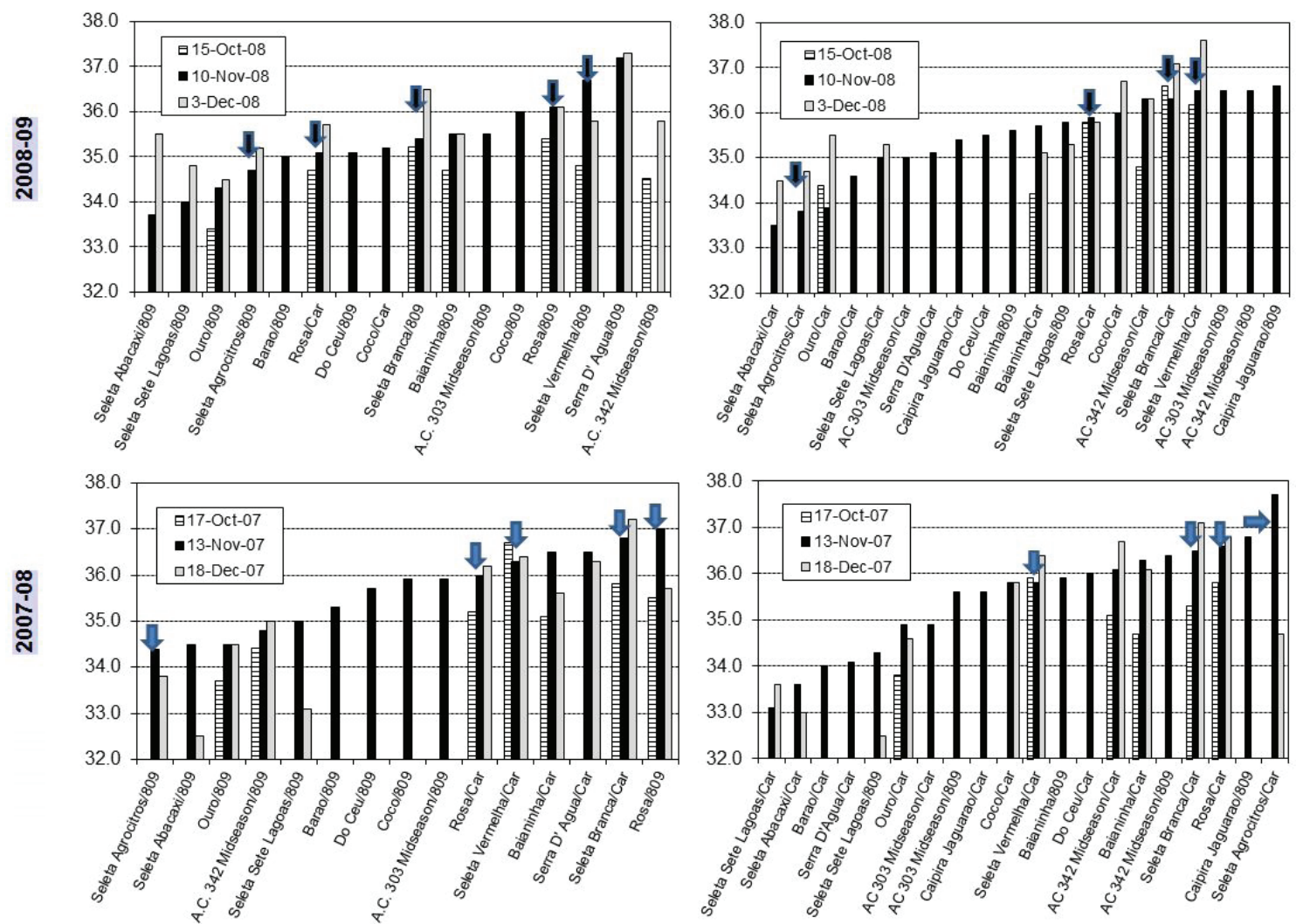

Figure 1. Juice color numbers of various early-maturing sweet orange selections grown in Lake Alfred over two seasons (left panels) and in Vero Beach (right panels). The arrows point to those selections considered the most promising.

Credits: William S. Castle

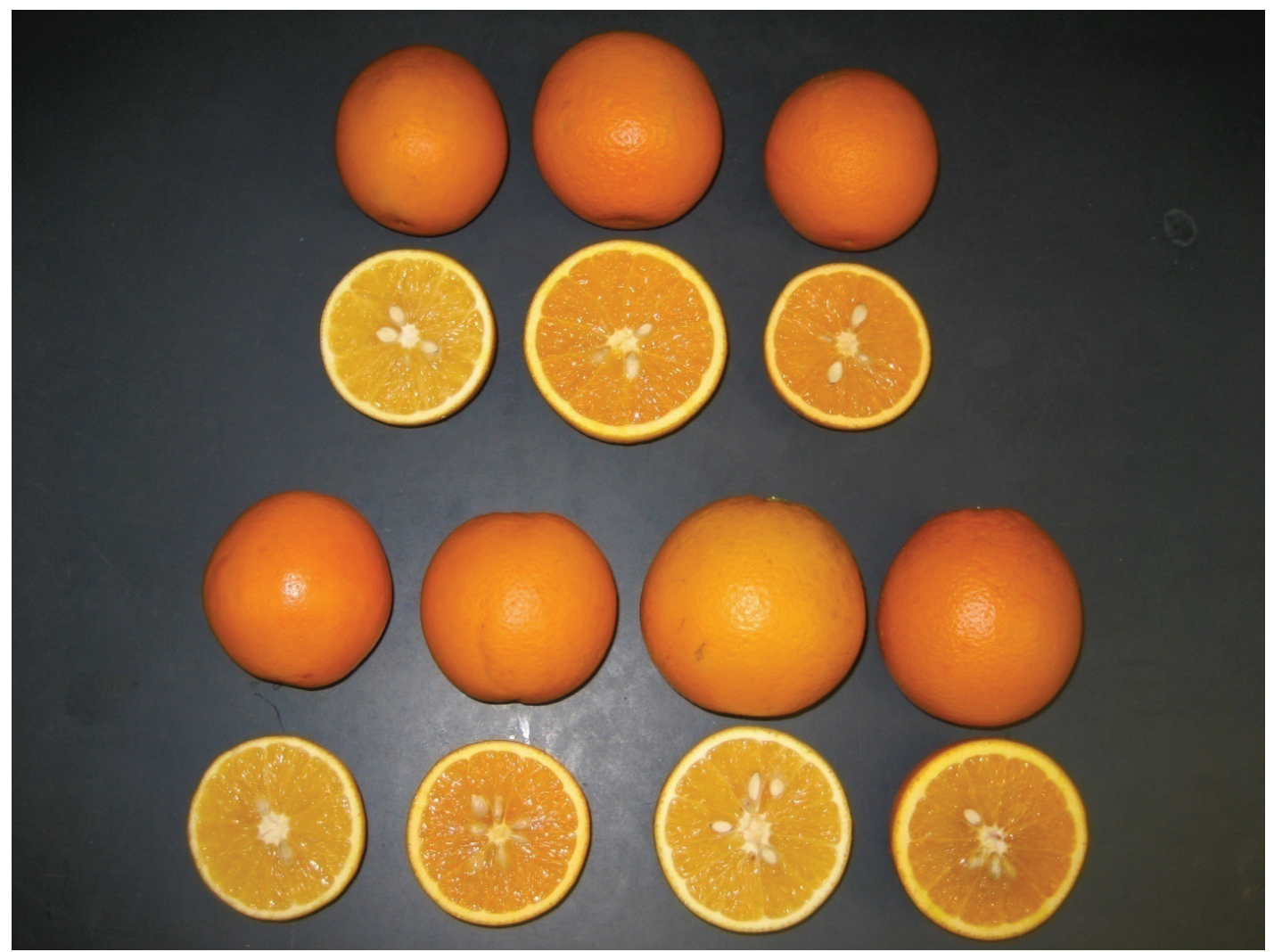

Figure 2. Fruit of selections in mid-November and under evaluation at a site in Lake Alfred. Top row, L-R: 'Barao', 'Seleta Branca', and 'Serra D'Agua'; bottom row, L-R: 'Hamlin', 'Earlygold,' 'Ouro', and 'Rosa'.

Credits: William S. Castle 

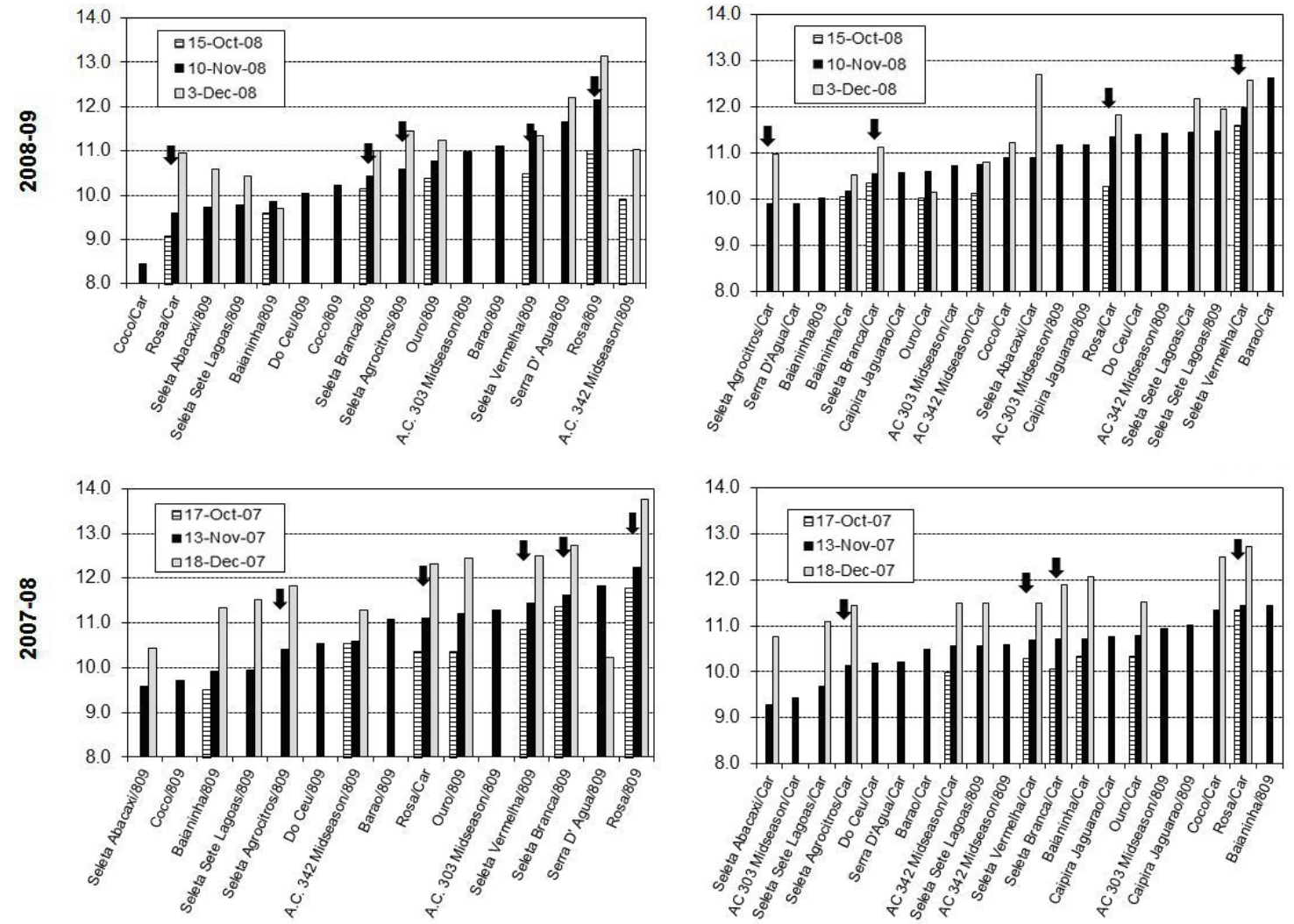

Figure 3. Juice soluble solids concentrations of various early-maturing sweet orange selections grown in Lake Alfred over two seasons (left panels) and in Vero Beach (right panels). The arrows point to those selections considered the most promising.

Credits: William S. Castle
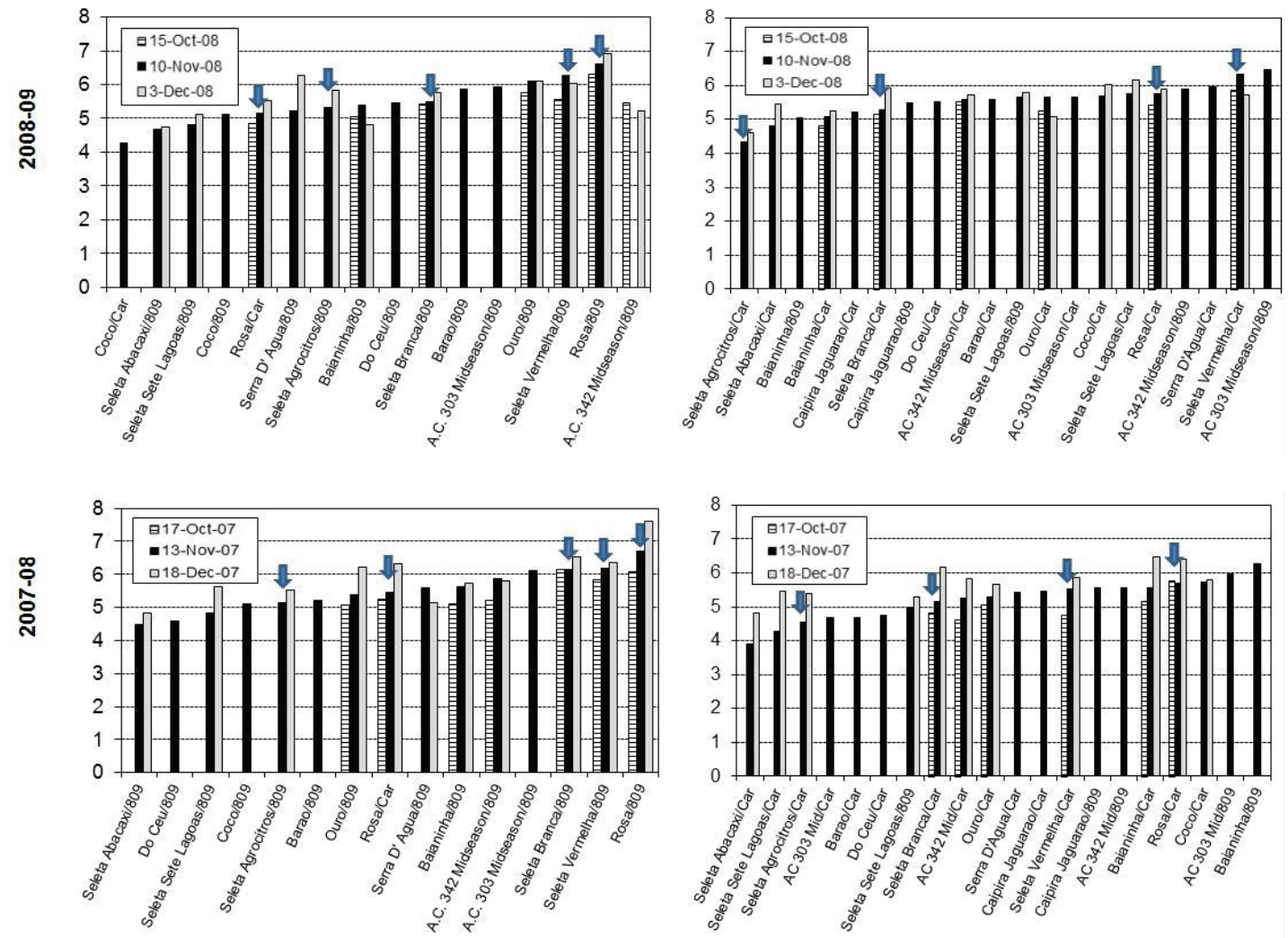

Figure 4. Pounds-Solids/box in the juice of various early-maturing sweet orange selections grown in Lake Alfred over two seasons (left panels) and in Vero Beach (right panels). The arrows point to those selections considered the most promising.

Credits: William S. Castle 

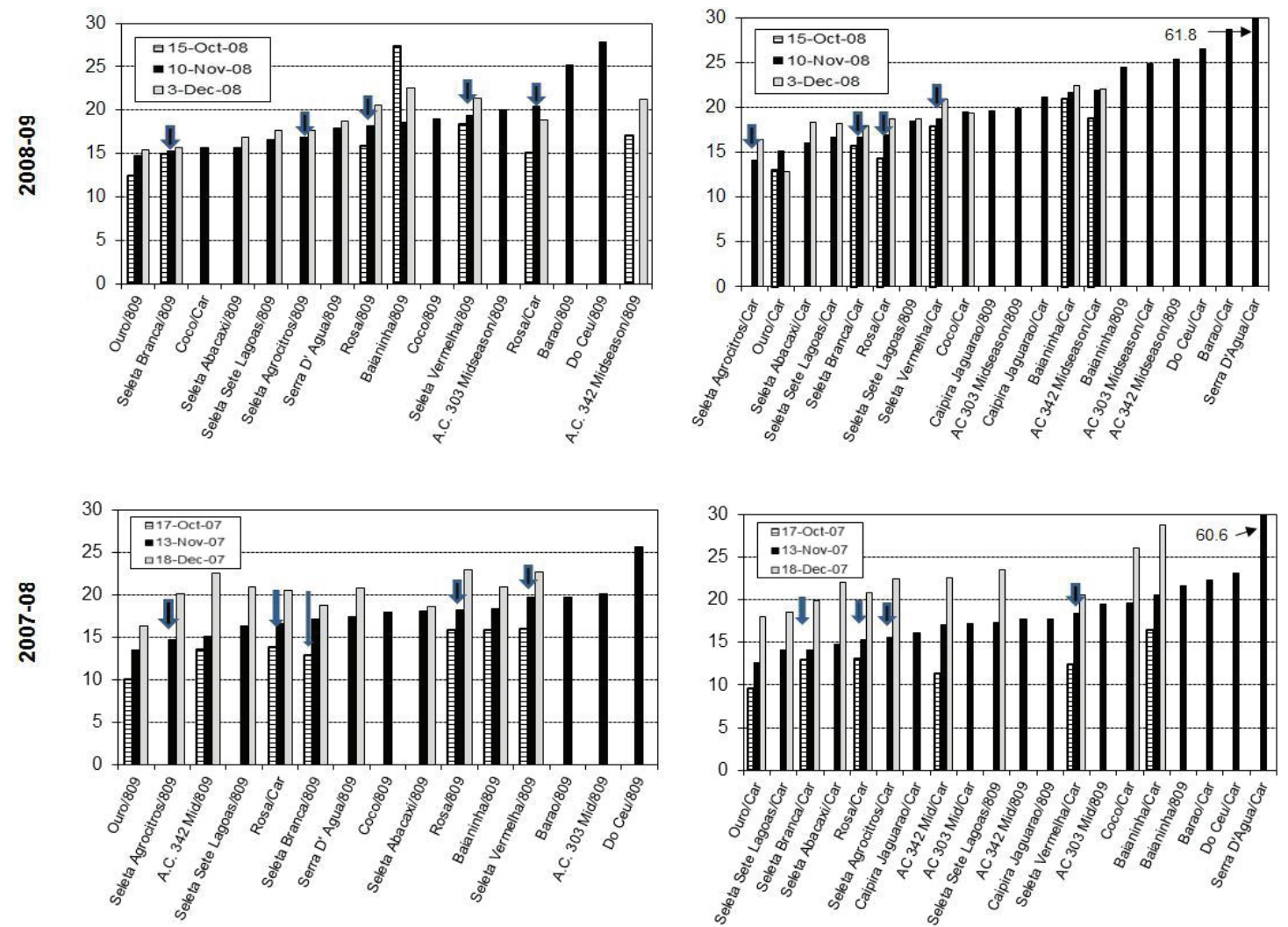

Figure 5. Juice soluble solids-acid ratios of various early-maturing sweet orange selections grown in Lake Alfred over two seasons (left panels) and in Vero Beach (right panels). The arrows point to those selections considered the most promising.

Credits: William S. Castle 
Archival copy: for current recommendations see http://edis.ifas.ufl.edu or your local extension office.

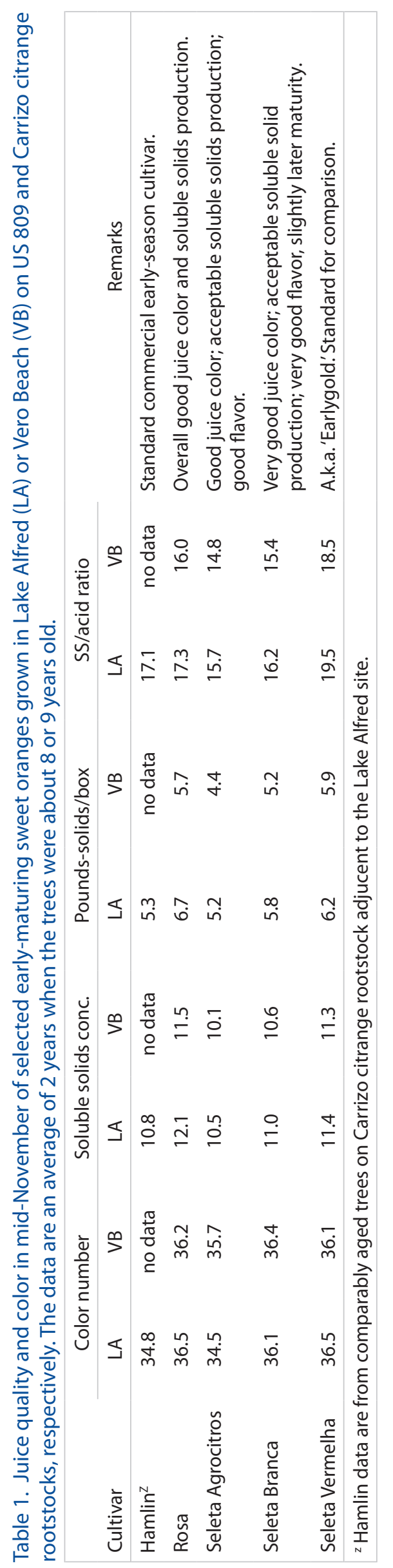

